The Changing Face of Mainstream Economics

by

David Colander

Ric Holt

Barkley Rosser

November 2003

MIDD LEBURY COLLEGE ECONOMICS DISCUSSION PAPER NO. 03-27

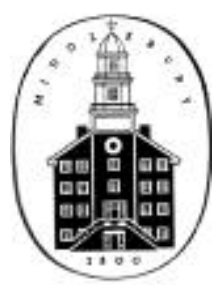

DEPARTMENT OF ECONOMICS

MIDDLEBURY COLLEGE

MIDDLEBURY, VERMO NT 05753

http:/ / www.middlebury.edu/ econ 


\title{
The Changing Face of Mainstream Economics
}

\author{
David Colander, Ric Holt and Barkley Rosser
}

\section{Introduction}

If one reads the heterodox literature in economics these days, one gets the impression that modern mainstream economics is much like the economics of 50 years ago; it is called neoclassical economics and is criticized in much the same way that earlier heterodox economists criticized the mainstream economics of the 1950s or 1960s. In this paper we argue that much of this criticism today is off the mark because mainstream economic thinking has changed. We argue that economics is moving away from a strict adherence to the holy trinity - rationality, selfishness, and equilibrium - to a more eclectic position of purposeful behavior, enlightened self-interest and sustainability. The paper develops our ideas by considering the nature of that change and the process and sociological dynamics by which the profession changes.

\section{The Profession as a Complex System}

To understand our argument it is helpful to think of the profession as a complex system. Complex systems cannot be understood from assumed first principles; they can only be understood through the process of change that underlies them. In the same way, the economics profession can best be understood by the process of change that characterizes it. Most considerations of the economics profession have tended to take a static view of the profession, which makes it seem as if it is an unchanging entity. That's the approach that most heterodox criticisms of the profession have taken. That's not the way we see the economics profession; we see it as a dynamic entity, which generates a self-reproducing, evolving, complex system of interacting ideas.

Getting a handle on such a dynamic entity and conveying its essence to others often requires giving it static classifications and organizing it into distinct periods. Historians of economic thought must do this to provide structure for their consideration of past economists. But these classifications are crutches, not characterizations of reality. They are imposed by the observer and are not necessarily part of the essence of the profession at any point in time. Any static classification hides the dynamic change occurring underneath it. For this reason the classifications used by historians of thought, such as Classical or Neoclassical, while useful and perhaps even necessary, are nevertheless confining and miss important dimensions of the profession.

\section{The Edge of Economics}

The changes in the profession are brought about by what we call work at the edge of economics. ${ }^{1}$ It is innovative and successful work at the edge of the profession that signals

\footnotetext{
${ }^{1}$ The term, edge of economics, refers to work challenging the previously considered "orthodox" ideas. Initially, we described it as cutting edge work, but some of our colleagues have pointed out that cutting
} 
the future direction of change in economics and how the profession eventually comes to be viewed and understood by its elite. The very concept of an edge of the profession is designed to suggest a profession in which there are multiple views held within the profession, and goes against the standard classifications of economics. Those standard classifications convey a sense of the profession as a single set of ideas. In our view, that is wrong; it is much more useful to characterize the economics profession as a diverse evolving set of ideas, loosely held together by its modeling approach to economic problems. $^{2}$

Standard classifications tend to miss the diversity that exists within the profession, and the many new ideas that are being tried out. They miss the important insight that one can be part of the mainstream and yet not necessarily hold "orthodox" ideas. Standard classifications also emphasize a fairly narrow orthodox core of the profession and convey a picture of all conventional economists accepting this core. The reality is more complicated; conventional economists often hold a variety of views simultaneously. If the variance of views increases, while the core remains relatively unchanged, the static characterization of the profession will not change, but its dynamic characterization will.

A large variance in acceptable views, such as has emerged in the profession over recent decades, signals that changes are likely in the future. In our view the interesting story in economics over the past decades is the increasing variance of acceptable views, even though the center of economics has not changed much. For example, mainstream economists today such as William Baumol, George Akerlof, Thomas Schelling, Truman Bewley, and Paul Krugman, in important aspects of their thinking, are working outside of what is generally considered the orthodoxy of the profession. Yet, their ideas are widely accepted and discussed within the mainstream of economics. It is such work that has increased the variance of acceptable views in the profession.

To capture that variance of acceptable views, static classifications must be seen for what they are-useful fictions that are meant for students and non-specialists. These classifications are backward looking, and, to be meaningful, they must be supplemented with a discussion of the variance of ideas acceptable to the mainstream. The reality is that an an point in time a successful discipline will have hundreds of new ideas being tried out, as new methods, new technology and new information become available. That is what happens at the edge of economics.

This edge of economics has both intellectual and social elements. The intellectual aspect of economics at the edge fundamentally involves originality. This does not mean that all ideas at the edge are totally new. Ideas have origins, and grow better in some environments than in others. The history of economics is full of instances in which old ideas are rehabilitated or revived and found to be useful and advantageous within the new context that is emerging.

\footnotetext{
edge work can only be defined historically as work at the edge that has panned out. Comments by Larry Moss, and Ken Koford were very helpful in redirecting us in our terminology.

${ }^{2}$ Robert Solow (1996) writes "Today if you ask a mainstream economist a question about almost any aspect of economic life, the response will be: suppose we model that situation and see what happens...modern mainsteam economics consists of little else but examples of this process."
} 
In the work at the edge ideas, which previously have been considered central to economics are being modified and broadened, and the process is changing the very nature of economics. What is making it possible for these ideas to take root now, but not in the past, are advances in analytic technology, such as non-linear dynamics, which has made it possible to study much more complex models than before, developments in computing capabilities, which have made studies with simulations and agent-based models much more useful, allowing economists to study problems that do not have analytic solutions. Combined with advances in other disciplines relevant to economics, which makes the integration among disciplines easier, the combination of these advances has opened up completely new ways of integrating those ideas into the core beliefs of the field, and has changed the core beliefs in important ways. For example developments in nonlinear dynamics are now allowing alternative models of processes that include sudden shifts from one equilibrium to another, and the development of agent-based modeling is allowing researchers to explore models with heterogeneous agents and to move away from a focus on unique equilibria.

\section{Change within the Profession}

Sociological issues impinge upon and constrain what is possible intellectually. The reproduction of ideas involves the social, political, and economic structures of the academic and policymaking establishments in which ideas are developed and transmitted. Ideas, however original and possibly wonderful, that do not become accepted by some of the elite of the profession, and which do not eventually get funded, will not be accepted and transmitted within the profession. To internally move the discipline to a new position some of the profession's elite must accept these ideas.

In our view what is occurring in economics today is a modification of the standard view of paradigm shifts proposed by Thomas Kuhn (1970), at least as it relates to the economics profession. Kuhn argued that the driving forces of change are those ideas that challenge the very system of thought in a way that puts them outside the mainstream, and ultimately are only introduced, "funeral by funeral" by a paradigm shift. This makes it easy to recognize that a paradigm shift has occurred.

We see this view as not quite fitting the economics profession. From our dynamic perspective an alternative channel exists that allows for significant changes to occur within the mainstream of the profession. These changes do not lead to sudden paradigm shifts, but instead lead to cumulative evolutionary changes that ultimately will be recognized as a revolutionary change. The changes that lead to this ex-post revolution were initially accepted within the profession gradually, more along the lines suggested by Imre Lakatos (1978). This alternative channel is the following: When certain members of the existing elite become open to new ideas, that openness allows new ideas to expand, develop, and integrate into the profession. In that case change within the profession can be accepted gradually, being introduced "data set by data set" and "new technique by new technique" as well as "funeral by funeral". In some cases these new ideas will originate from outside the mainstream, from those who consider themselves heterodox, even if the acceptance of such ideas leads to their "normalization" and removal from being identified as heterodox. 
These alternative channels allow the mainstream to expand and evolve to include a wider range of approaches and understandings. Eventually, sufficient change is made so that future historians of thought will consider the orthodoxy of the period changed. This, we believe, is already occurring in economics. Mark Blaug, one of the most distinguished current historian of economic thought, has pointed out that beginning as early as the 1950 s the classification "neoclassical economics" was no longer appropriate to characterize modern economics (1998, p.2), an argument further developed by Colander (2000a).

The difference between Kuhn's view and ours is in how changes generally come about in a profession. We suggest that changes, even ones that will eventually be considered revolutionary, often come from within and will not be noticed for years. Kuhn's view suggests that they can only come from outside and are quite apparent when they occur. The dynamic approach of change within the profession that we are introducing here involves stealth changes, in which advocates of new ideas may gain acceptance among the elite of the profession and even achieve positions of power and prominence within at least some leading academic institutions of economics. The change, however, is so gradual that the profession often does not notice that the change has occurred.

The reason for the difference is the multiple dimensionalities that we see in the mainstream profession. It is a complex system of evolving ideas. Individuals in the profession see minute changes upon minute change but do not have a perception of the aggregate of the changes. Only when historians of thought look back, after sufficient time has passed to gain some historical perspective, does the larger change become apparent.

\section{The Process of Change}

Both the social and intellectual aspects of change must be taken into account in order to understand the evolution of ideas. The work at the edge is generally begun by younger researchers and in some cases those who are doing heterodox work. But their ability to do that work, and to have their work affect the profession, is dependent on the existence of crucial persons in the leading academic establishments, representing the mainstream of economics, who are open to seriously considering new ideas. These crucial people may be the ones who have developed what was considered the old orthodoxy, but their having developed it doesn't mean that they aren't open to change and new ideas. There is nothing inconsistent with being one of the originators of a theory and simultaneously being a critic of that theory. Good economists simultaneously recognize the strengths and limitations of a theory, and are open to new approaches and ideas. A good example of a person that fits this category is Kenneth Arrow. Although he is associated with what is considered modern neoclassical orthodoxy, he was instrumental in the introduction of the complexity approach into economics. ${ }^{3}$

The consideration and ultimate acceptance of a new idea by a certain portion of the elite becomes a key to the process of how the conventional foundation of the discipline evolves. It is not crucial that those developing the ideas initially be at leading establishments. But they must be able to attract the attention of influential individuals at those institutions in order for their ideas

\footnotetext{
${ }^{3}$ Mirowski (2002, pp. 432-436) argues that an important influence on Arrow in his change of view was a former student, Alain Lewis (1985), whose work continues to be little known by most of the profession.
} 
to be published in venues that will receive attention, and for research along those lines to get funded. This allows students and advocates of those ideas to get hired at those institutions and thus to establish themselves within the mainstream of the discipline, even when the originators of these ideas remain somewhat outside the mainstream elite.

\section{Orthodoxy, Heterodoxy, Mainstream}

It is helpful in making our argument to carefully consider the terms, mainstream, orthodox, heterodox, how they are used, and how they relate to our idea that the dynamics of change in a profession is at the edge of the profession. Let's start with the term, mainstream economics. In some sense mainstream economics is the easiest of the above terms to define, although it may be the hardest to identify in practice. It is in large part a sociologically defined category. Mainstream consists of the ideas that are held by those individuals who are dominant in the leading academic institutions, organizations, and journals at any given time, especially the leading graduate research institutions. Mainstream economics consists of the ideas that the elite in the profession finds acceptable, where by elite we mean the leading economists in the top graduate schools. It is not a term describing a historically determined school, but is instead a term describing the beliefs that are seen by the top schools and institutions in the profession as intellectually sound and worth working on. Because of this, mainstream economics usually represents a broader and more eclectic approach to economics than is characterized as the recent orthodoxy of the profession.

In our view the term, orthodox, is primarily an intellectual category. It is a backward looking term that is best thought of as a static representation of a dynamic, constantly changing profession, and thus is never appropriately descriptive of the field of economics in its present state. Orthodoxy generally refers to what historians of economic thought have classified as the most recently dominant "school of thought," which today is "neoclassical economics." In our view modern mainstream economics is quite different from this neoclassical concept of orthodox economics. Having the two terms is important for us because it allows us to make intertemporal comparisons between the most recently dominant school of thought, in this case neoclassical economics, and today's evolving mainstream economics.

To help us get a grasp of what we mean by neoclassical orthodoxy and how it relates to mainstream economics, it is important for us to first specify what we see as neoclassical economics. In our view neoclassical economics is an analysis that focuses on the optimizing behavior of fully rational and well-informed individuals in a static context and the equilibria that result from that optimization. It is particularly associated with the marginalist revolution and its aftermath. Léon Walras and Alfred Marshall can be viewed as its early and great developers, with John Hicks's Value and Capital (1939) and Paul Samuelson's Foundations of Economic Analysis (1947) as its culmination. When a dynamic context is assumed, individuals understand the probability distributions of possible outcomes over the infinite time horizon at the moment of decision. The neoclassical orthodoxy tests the results of that model by using conventional econometric techniques that are based upon a foundation of classical statistics. Perhaps the most important characteristic of the neoclassical orthodoxy is that axiomatic deduction is the preferred methodological approach. 
The difference between mainstream and orthodox becomes clearer when one recognizes two other aspects of the term orthodox. The first is that the name and specification of what is orthodox usually comes decades after the time period has existed. Thus, orthodox specifications inevitably are backward looking, not current or forward-looking. Second, in economics at least, the name for the orthodox school has usually come from a dissenter, who opposed the orthodox ideas, not from a supporter of the orthodox ideas. For example, Marx (1847) coined the term classical economics, even though the Classical school is seen as starting back in the late 1700s. Before Marx's general classification there was no name for the classical orthodoxy.

Similarly the term neoclassical economics was coined by Veblen (1900), referring to economics of the last part of the 19th Century as he tried to tie this period of economics to Classical economics, so as to make the argument that both are unscientific (Aspromourgos, 1986). In each case, the classification was made by an economist so as to create a better target for his criticism. Defining orthodoxy, and giving a name to it, gives a critic an easy target; it implies a static unchanging dimension of thought. But this static view is not characteristic of the economics field. At any point in time, and especially by the time that the term becomes generally used, a large part of the mainstream profession disagrees with important dimensions of what is then thought of as orthodoxy.

Finally, let's consider the term heterodox. It is usually defined in reference to orthodox, meaning to be "against orthodox," and defines itself in terms of what it is not, rather than what it is. An economist who sees him or herself as heterodox does not subscribe to the current orthodox school of thought, as defined by the historian's classifications. However, in our view heterodoxy also has a sociological aspect. A self-identified heterodox economist has also defined his or her self outside of the mainstream. Heterodox economists are highly unlikely to get funding through normal channels such as the National Science Foundation, although they might receive alternative funding from a variety of sources. Thus, heterodoxy involves both sociological and intellectual aspects. Since many mainstream economists also do not accept important aspects of the orthodoxy, the additional feature that determines a heterodox economist is social; heterodox economists refuse to work within the framework of mainstream economics whether because of the nature of the modeling process used, or the assumptions emphasized. This often causes a failure to communicate between heterodox and mainstream economists, even when they may share similar views about the limitations of the "orthodox" approach.

In the economics profession various schools, many of which have long histories, comprise heterodox economics. These schools have their own networks and organizations and journals and academic institutions where they dominate. Often the fundamental intellectual content of a heterodox school is rejection of orthodoxy, or at least major elements of orthodoxy. In economics, at least, beyond this rejection of the orthodoxy there is no single unifying element that we can discern that characterizes heterodox economics. In fact, it is well known that many varieties of heterodoxy have more disagreement with each other than they do with orthodoxy. But it should also be said that different heterodox schools previously emphasized many of the ideas that are now on the edge of economics, and these schools can play an important role in developing new critiques of the orthodox. Among the most established of the heterodox schools 
with reasonably full systems of institutional support are Marxists, Post Keynesians, feminists, Old Institutionalists, and Austrians. ${ }^{4}$

If the field of economics were static and one-dimensional, these two classifications, orthodox/heterodox, would be sufficient, but it isn't and they aren't. The economics profession is dynamic, constantly changing. Since these classifications usually lag developments in the field by decades, the terms, orthodox and heterodox, when used in a current setting, tend to be backward-looking, describing beliefs that, while they still may show up in texts, are not strong convictions of many in the profession, and are being attacked by economists at the edge of the profession.

To understand the dynamic aspect of the profession and the role of economists working at the edge, the distinction between mainstream and orthodox is central. The edge of economics is that part of mainstream economics that is critical of orthodoxy, and that part of heterodox economics that is taken seriously by the elite of the profession. Our argument is that modern mainstream economics is open to new approaches, as long as they are done with a careful understanding of the strengths of the recent orthodox approach and with a modeling methodology acceptable to the mainstream.

For an economist working at the edge, attacking the profession is not sufficient; he or she must be developing new methods and ideas. In this approach the difference between mainstream and heterodox becomes far less important than whether they are doing work at the edge. In this case, both mainstream and heterodox economists are working on issues that challenge the neoclassical orthodoxy, because that orthodoxy is no longer descriptive of what the mainstream elite believes. The elite's vision of economics is forward looking - these are the ideas that are exciting today, and here is where they may lead; the static classifications of economics are backward looking, emphasizing where economics has been.

This concept "elite of the profession" is elusive, but is understood by those in the profession. It is those mainstream economists who have made important contributions to thought in the past. It includes some (but not all) Nobel Prize winners, and most economists who have major chairs at top graduate programs. If one has standing offers from a number of top schools to come and teach there if one desires, and if one receives calls from NSF about who to put on NSF panels, one is in the elite of the profession. Examples of well-known mainstream elite are Paul Samuelson, Kenneth Arrow, Robert Solow, Thomas Schelling, Amartya Sen, Joseph Stiglitz, Chris Sims, Michael Woodford, George Akerlof, Richard Thaler, Anne Krueger, and Jagdish Bhagwati. As you can see it is a very diffuse group.

Recognizing that there is an elite element in the mainstream that plays a crucial role in what new ideas will prove to be part of the acceptable edge of economics raises two problemsone of how open the elite will be, and another of how these ideas then disseminate throughout the rest of the mainstream and the profession more generally. Currently, our view is that the elite are relatively open minded when it comes to new ideas, but quite closed minded when it comes

\footnotetext{
${ }^{4}$ We recognize that this characterization oversimplifies the state of heterodox economics. Not only are there many subcategories and schools within these main branches of heterodoxy, but there are many other schools or approaches as well.
} 
to alternative methodologies. If it isn't modeled, it isn't economics, no matter how insightful. It is here where the heterodox and mainstream elite normally collide. Specifically, it is because of their method, not their ideas, that most heterodox find themselves defined outside the field by the elite. $^{5}$

We certainly are not claiming that the mainstream is always pluralistic and open minded, willing to accept heterodox views with open arms. Far from it. They are human, and become fixed in their ways of looking at things and often reject alternative views without giving them serious consideration. That's part of human nature. This means that in many unconscious ways, which we consider unfortunate, the mainstream elite can suppress the views of heterodox economists. Moreover, they often use their method as a tool to protect views which don't fit nicely into their way of thinking. What we are claiming is that their close-mindedness is generally unconscious, and representative of almost any group that has the power to be that way, including in their own small spheres, many heterodox economists. What we are also claiming is that the worst types of heterodox suppression and narrow-mindedness is not carried out by the elite, but instead by economists whose professional credentials are mediocre for the very reason that they are not as imaginative and creative as the elite.

Once an idea is expressed in an acceptable model the dissemination process is a long and drawn-out one that works along the following lines. Work at the edge usually shows up first in working papers that are presented at graduate seminars and workshops that are the incubators of new ideas in economics, although sometimes these ideas were initially generated by persons outside of those seminars. The ideas in these working papers will generate discussion among professors at graduate schools; some will be panned; others will be tentatively accepted, and mentioned to professors at other schools. Some ideas will generate a buzz, and when they do, will attract intense interest. (This generally occurs before publication.) Eventually the idea will be published in a top journal, but that publication is often a tombstone process demarking ownership of the idea more than it is a spreading of the idea. The diffusion of the idea throughout the elite of the profession will have already occurred, although sometimes an idea will be published and not get noticed until sometime later.

As this process is occurring the working paper or article will show up in core graduate program reading lists, and eventually make its way into graduate textbooks. This process from conception of the idea to graduate textbooks can take up to ten years. Intermediate and upper level undergraduate textbooks usually take another five to ten years to include these ideas, although they may show up as a supplemental box, or an added paragraph earlier than this. Principles books take another five to ten years to actually incorporate the idea as a central element, although, like their undergraduate upper level counterparts, they may add them as addenda so that they look modern.

There is a paradox in this diffusion process. The more central the idea, the less likely it is to be included in a central way in the texts. For example, complexity suggests the whole conception of equilibrium in an economy needs to be reconsidered, and experimental economics suggests that the entire approach to thinking about the appropriate mix of induction and deduction needs to be rethought. Such a reconsideration and rethinking would likely change the

\footnotetext{
${ }^{5}$ See Colander (2003) for a development of this point in reference to institutionalists.
} 
entire way textbook are structured, and the way the courses are taught. Such major changes are unlikely to show up even with the long lags that we discussed. Instead they will be simply added as an addendum to the existing core. (For a discussion of these issues, see Colander, 2000b) Such changes resemble more the kind of changes that Kuhn discussed in his analysis of paradigm shifts, even if the shift has occurred in the more gradualist manner that we have been describing.

Why the enormous lag? The reason is that the professors who actually teach the majority of the courses are most comfortable teaching what they have studied, and the publishing industry writes for that majority. Since the average undergraduate professor has been out of graduate school for a long period of time, the average professor (which the textbooks target as their audience) will generally be most comfortable teaching older material as the core of the course, with new material scattered throughout. The material shows up in higher level courses first because the higher the level of the course the more likely a specialist in the area is teaching the course, and that specialist is more likely to feel comfortable including new developments.

This long lag should not be seen as a complete waste; it also serves a useful function in that it provides a filtering process that eliminates those ideas that seemed wonderful, but turned out to be just fads. For example, the Keynesian IS/LM model has remained the core of many undergraduate macro texts even after it has all but been excluded from what is taught in graduate schools. New books reflecting the new graduate school approach have been published, but they have not been generally adopted at the undergraduate level.

This lack of acceptance by the undergraduate texts reflects the uncertainty with which many in the mainstream profession both at the undergraduate and graduate level saw with the rational expectations revolution in macro. While it was a logical extension of microeconomic reasoning, it did not seem reasonable to many, suggesting that something was wrong with the models that were based on it in its strong form. For that reason the rational expectations revolution led to work in what might be called the complexity revolution, which is striving to provide stronger underpinnings for macro models generally. This work begins from the assumption of rationality, but seriously considers the problems of defining rationality in a complex environment, and when there are problems, accepts the complex environment as its reference point, rather than taking a simpler environment.

The lags in this process can lead to situations where an idea that has come to be viewed as somewhat old hat at the elite mainstream level may only finally be appearing at the principles textbook level. What this means is that textbooks, especially lower level texts, often do not reflect the diversity of views acceptable to the mainstream, but instead reflect an older orthodox position. ${ }^{6}$

Another important comparison between the mainstream and orthodoxy is that economists working within the mainstream can find their views evolving. For example, they might be working with a particular approach, but then change. Consider rational expectations and the New

\footnotetext{
${ }^{6}$ This lag of textbooks of mainstream thinking can be seen in earlier times as well. In his writings John Stuart Mill gave up the wage fund doctrine, but retained it in his principles book stating that these new developments "are not yet ripe for incorporation in a general treatise on Political Economy." (Mill p. xxxi)
} 
Classical revolution in macroeconomics. One of the early developers of rational expectations, Leonard Rapping, modified his views significantly and became a leading heterodox economist before his untimely death. Another example is Thomas Sargent, another of the leading figures in the application of rational expectations to macroeconomics. As a result of visiting the Santa Fe Institute he came to abjure a strict rational expectations view (Sargent, 1993). His more recent work with Lars Hansen and others (Hansen and Sargent, 2000) has attempted to provide quantitative approaches to dealing with Knightian uncertainty, and thus he has moved out of orthodoxy, but has remained mainstream, and is on the edge of the edge of economics.

As should be clear from the above discussion, in our view the edge is where the action is in the profession. Whether what works at the edge is considered heterodox or mainstream is primarily a matter of the individual's proclivity to fit within the existing mainstream, and the degree to which they directly attack, rather than softly criticize, the work of the elite. It should be pointed out that working at the edge does have its problems, especially for those whose proclivity is toward attacking, rather than working within the existing field, and hence finding themselves in heterodoxy. They face significant sociological problems of achieving acceptance from the established mainstream. Economists considered heterodox often find it difficult gaining funding for their work, and they will be squeezed out of the decision making process at their universities. Those involved in working at the edge that are in the mainstream lack this sociological problem, but also often find themselves at odds with those around them to some degree as they press against the boundaries of the mainstream.

\section{Work at the Edge of Economics and the Complexity Vision}

We emphasize complexity as a defining factor of the new work at the edge of economics, because it appears to us to be the vision behind this work. But the actual work involves a number of fronts, and the people working on those fronts have varying degrees of connection to the broader complexity approach. Along with this, and interacting with it, is a new openness to ideas from other disciplines. Thus, modeling remains the central core of the mainstream approach, but the nature of the models and the assumptions underlying them are much more open, and transdisciplinary. ${ }^{7}$ More specifically:

- Evolutionary game theory is redefining how institutions are integrated into the analysis.

- Ecological economics is redefining how nature and the economy are viewed as interrelating.

- Psychological economics is redefining how rationality is treated.

\footnotetext{
${ }^{7}$ There is much discussion now regarding how one is to describe research that involves more than one discipline. The oldest term is probably multidisciplinary. However, this now usually is applied to situations where persons representing different disciplines get together and contribute ideas from their separate disciplines in ways that maintain the distinct identities of their disciplines, as in separate chapters within a book. A more recent term of use has been interdisciplinary that involves more integration of the ideas of different disciplines. However, this is often used in the sense of dealing with ideas that exist in the intersection of two disciplines, leading to particular specializations, e.g. "water economist," who knows about relevant aspects of both hydrology and economics. Following the lead of the ecological economists we favor the term transdisciplinary to describe the new developments at the edge, which implies a more thoroughgoing and profound interaction between the disciplines leading to some kind of new synthesis and transcendence.
} 
- Econometric work dealing with the limitations of classical statistics is redefining how economists think of empirical proof.

- Complexity theory is offering a way of redefining how we conceive of general equilibrium.

- Computer simulations are offering a way of redefining models and how they are used.

- Experimental economics is changing the way economists think about empirical work.

These changes in turn have led to a broader set of changes in how mainstream economics sees itself. It is much more willing to accept that the formal part of economics has limited applicability, at least as currently developed. It is also far more willing to question economics' special status over the other fields of inquiry and integrate the methods of other disciplines into their methods.

The change that is occurring in economics is most clearly symbolized by two conferences held nearly a decade apart at the Santa Fe Institute. The first held in 1988 generated a book entitled The Economy as a Complex Evolving System (Anderson, Arrow, and Pines, 1988). Waldrop (1992) reported that this conference featured a set of largely mainstream economists and defenders of general equilibrium orthodoxy, assembled by Kenneth Arrow, and a set of physicists assembled by others. The economists mostly attempted to defend their mainstream approach, while they faced sharp challenges and ridicule from the physicists for holding relatively simplistic views. Although models using nonlinear dynamics and other complexity approaches have been developed for some time (Rosser, 1999), such approaches at that time remained outside the mainstream camp.

The second conference saw a very different outcome and atmosphere than the first. (Arthur, Durlauf, and Lane, 1997). No longer were mainstream economists defensively adhering to general equilibrium orthodoxy. Now they were using methods adopted from biologists and physicists, many suggested at the earlier conference, in innovative ways. They were much more open to complex economic analysis.

These two Santa Fe conferences are representative of the change that occurred throughout the profession during this time. It was as if the ideas planted by earlier researchers in many areas, such as experimental economics, behavioral economics, and nonlinear dynamics, were taking root. Thus, by 1997 the mainstream accepted many of the methods and approaches that were associated with the complexity approach. What they had not accepted was the broader complexity vision. (For a discussion of that broader vision, see Colander, 2000c). That broader vision is held by a much smaller group of economists, and it may or may not be held by the individuals working on the edge of economics. But as the work at the edge progresses and accumulates, it shifts the center of economist's approach, and, in our view, eventually will create a new orthodoxy centered on a broader complexity vision.

\section{References}


Alchian, A.A. (1950) Uncertainty, evolution and economic theory, Journal of Political Economy, 58, pp. 211-222.

Anderson, P.W., Arrow, K.J. \& Pines, D. (Eds) (1988) The Economy as an Evolving Complex System (Redwood City, Addison-Wesley).

Arthur, W.B., Durlauf, S.N. \& Lane, D.A. (Eds) (1997) The Economy as an Evolving Complex System II (Redwood City, Addison-Wesley).

Aspromourgos, T. (1986) On the origin of the term 'neoclassical', Cambridge Journal of Economics, 10, pp. 265-270.

Blaug, M. (1998). The formalist revolution or what happened to orthodox economics after World War II, University of Exeter, 98/10 Discussion Paper in Economics.

Colander, D. (2000a) The death of neoclassical economics, Journal of the History of Economic Thought, 22, pp. 127-143.

Colander, D. (2000b) A thumbnail sketch of the history of thought from a complexity perspective, in: D. Colander (Ed.) Complexity and the History of Economic Thought (New York, Routledge).

Colander, D. (Ed.) (2000c) Complexity and the Teaching of Economics (Cheltenham,Edward Elgar).

Debreu, G. (1991) The mathematization of economic theory, American Economic Review, 81, pp. 1-7.

Hansen, L.P. \& Sargent, T.J. (2000) Wanting robustness in macroeconomics, ftp://zia.Stanford.edu/pub/sargent/webdocs/research/wanting.pdf.

Hicks, J.R. (1939). Value and Capital (Oxford, Clarendon Press).

Kuhn, T.S. (1970) The Structure of Scientific Revolution, enlarged ed. (Chicago, University of Chicago Press).

Lakatos, I. (1978) The Methodology of Scientific Research Programmes: Philosophical Papers, Vol. 1 (Cambridge, Cambridge University Press).

Lewis, A. (1985) Complex structures and composite models - an essay on methodology, Mathematical Social Sciences, 10, pp. 211-246.

Marx, K. (1847) The Poverty of Philosophy, English translation in (1977) Karl Marx and Friedrich Engels: Collected Works (New York, Progress Publishers).

Mill, J.S. (1929) Principles of Political Economy with Some of Their Applications to Social Philosophy, W. J. Ashley (Ed.) (London, Longmans, Green).

Mirowski, P. (1989) More Heat than Light: Economics as Social Physics, Physics as Nature's Economics (Cambridge, Cambridge University Press).

Mirowski, P. (2002) Machine Dreams: Economics Becomes a Cyborg Science (Cambridge: Cambridge University Press).

von Neumann, J., completed by Burks, A.W. (1966) Theory of Self Reproducing Automata (Urbana, University of Illinois Press).

Rosser, J.B., Jr. (1999) On the complexities of complex economic dynamics, Journal of Economic Perspectives, 13(4), pp. 169-192. 
Samuelson, P.A. (1947) Foundations of Economic Analysis (enlarged ed., 1983) (Cambridge, Harvard University Press).

Sargent, T.J. (1993) Bounded Rationality in Macroeconomics (Oxford: Clarendon Press).

Smith, A. (1776) An Inquiry into the Nature and Causes of the Wealth of Nations (London, Strahan and Cadell).

Smith, V.L. (1992) Game theory and experimental economics: beginnings and early, in: E.R. Weintraub (Ed.) Toward a History of Game Theory, History of Political Economy Annual Supplement, 24, pp. 241-282.

Solow, Robert. 1997. "How Did Economics Get That Way and What Way Is It?" Daedalus, (Winter) 39-58

Veblen, T. 1900. Preconceptions of economic science, part III, Quarterly Journal of Economics, 14, p. 261.

Waldrop, M.M. (1992) Complexity: The Emerging Science at the Edge of Order and Chaos (New York, Simon \& Schuster).

Walker, D.A. (1996) Walras's Market Models (Cambridge, Cambridge University Press).

Weintraub, E.R. (2002) How Economics Became a Mathematical Science (Durham, Duke University Press).

Woodford, M. (Ed.) (forthcoming) Festschrift in Honor of Edmund Phelps (Princeton, Princeton University Press). 